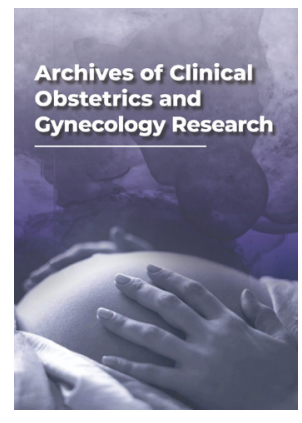

Correspondence

Dr. PH Iris Brandes, MPH

Department of Epidemiology, Social Medicine and Health System Research, Hannover Medical School, Carl-NeubergStraße 1, 30625 Hannover, Germany Tel.: +49 (0)511 532 - 9834

E-mail: Brandes.Iris@mh-hannover.de

\footnotetext{
- Received Date: 14 Aug 2020;

- Accepted Date: 24 Aug 2020;

- Publication Date: 05 Sep 2020.
}

\section{Keywords}

Endometriosis; Onset of Symptoms; Diagnostic delay; Qualitative Methods; Health Services Research

\section{Copyright}

(c) 2020 Science Excel. This is an openaccess article distributed under the terms of the Creative Commons Attribution 4.0 International license.

\title{
Relationship between onset of symptoms and diagnostic delay in women with endometriosis
}

\author{
PH Iris Brandes and Bettina Kruckenberg \\ Department of Epidemiology, Social Medicine and Health System Research, Hannover Medical School, Hannover, Germany
}

\begin{abstract}
Introduction: Endometriosis, one of the most common benign gynaecological diseases, is characterized by a reduced quality of life due to various physical and psychological stresses. Late diagnosis is associated with disease progression and higher healthcare costs. The aim of this qualitative study was to gain further insights into the causes of the delay in diagnosis in women with endometriosis.

Methods: Data basis are the statements of 90 women with diagnosed endometriosis from a qualitative study on the experience with health care in Germany. Following Kuckartz, structuredthematic content analysis was used to evaluate data. By comparing women with early and late onset of symptoms, possible causes for diagnostic delay were to be identified.

Results: Women who experience an early onset of symptoms, often associated with menarche, are predominantly not able to recognize the pathological condition of the symptoms. Lack of knowledge and experience regarding a normal menstrual cycle, intensive influence of family members and friends who tend to "normalize", "belittle" and describe the symptoms as fateful, late use of healthcare services as well as ignorance and misjudgement on the part of physicians result in a delayed diagnostic process.

Conclusion: The results of the present analysis confirm the findings of other studies indicating that misjudgment and ignorance of the signs and symptoms are the most important reasons for the delayed diagnosis of endometriosis. However, it will not be sufficient to bring about improvement exclusively at the level of the treating physician. Further measures should be taken to improve the level of knowledge of the general population. Thus, it is necessary to develop comprehensive and target group-specific information offerings to provide young girls with comprehensive and appropriate information as early as puberty.
\end{abstract}

\section{Introduction}

Although endometriosis is one of the most common benign gynecological diseases, there is a lack of reliable findings from representative studies on many important aspects, particularly epidemiological data [1,2]. The reported prevalence of treatment (i.e. documented contacts in a care or treatment facility) ranges from $0.8 \%$ to $2 \%$, and incidence rates are reported to be 1.4 to 7.2 per 1,000 [3]. The Federal Statistical Office of Germany documented around $28,000^{1}$ inpatient hospital stays due to endometriosis in 2017.

The economic burden resulting from endometriosis-associated operations, hormone therapies, fertility treatments and frequent absences from work illustrate the public health relevance of this disease is substantial [4-6]. The social impact of the disease, including the extension of training periods, missed career opportunities [7], reduced work productivity, lower social security benefits, and high treatment costs in predominantly young women, is also particularly relevant [8-11].

'Detailed diagnostic data of hospital patients (data record structure) 2017 Destatis, of 27.11.2018 (Table)
Primary symptoms of endometriosis include pelvic pain and infertility. Patients may have lower abdominal pain of various types, which can vary during the course of the disease. However, the severity of symptoms does not always reliably correlate with the extent of endometriosis [4]. Because the pathogenesis of endometriosis is still unresolved, no causal treatment options are available. The primary treatment goals, therefore, are to relieve pain and to eliminate fertility issues in women who wish to conceive. Many aspects of endometriosis have not yet been researched or are still insufficiently researched [2]. The complexity of the disease and its changeable, unpredictable course require individually personalized care. Possible problems in medical management of endometriosis must be identified as studies have shown that at least some women will experience undertreatment (e.g. lack of pain management), overtreatment (e.g. repeated surgery without symptom reduction) or mistreatment (e.g. due to incorrect diagnosis) in the course of the disease. A problem that has been discussed in the literature for several decades is the delay in diagnosis of endometriosis [12-15]. This time gap is associated with an increased individual burden of disease, 
wrong treatment and higher costs. Recent quantitative [16-18] and qualitative studies [12, 19-21] have provided first evidence of the possible causes.

On the basis of the data from a qualitative study of adult women with proven endometriosis, the present study was designed to identify possible causes of this diagnostic delay and to provide starting points for the improvement of endometriosis care. The research question of the study was: Are there differences between women with early onset endometriosis (EOE) symptoms versus late onset endometriosis (LOE) symptoms and, if so, could this be the cause of the delay in diagnosis?

\section{Database and Methods}

\section{Database}

The present results are based on extensive data from the EndoHealth Care (EHC) Study ${ }^{2}$, a qualitative study on the experience with care in the German health care system. By means of a broad recruitment process, 244 adult women with a diagnosis of endometriosis were recruited to participate in the study. Forty participants were selected for guideline-based face-to-face interviews and the remaining 204 were asked to complete a password-protected online questionnaire, which allowed for the anonymous collection of data, in $2015{ }^{3}$. Of the 102 returned questionnaires, four were unusable due to unreadable data and eight ${ }^{4}$ were excluded due to ambiguity resulting from unclear statements, leaving a total sample of 90 participants (P) with evaluable questionnaires. This sample formed the framework of the present analysis. Responses to the following questions were evaluated:

1. Onset of complaints: Please describe the beginning of the complaints

1.1. When did you first notice symptoms or complaints typical of endometriosis (e.g., severe pelvic pain, heavy bleeding)?

1.2. To what extent did you notice comparable complaints or symptoms at the beginning of menstruation?

1.3. How did you fare in the phase from the onset of the complaints until you consulted a doctor about your symptoms?

1.4. What effects did these complaints have on your everyday life?

2. Road to the diagnosis: Please describe your path to obtaining the diagnosis.

2.1. How did you manage the complaints or problems in the time before the diagnosis was made?

2.2. Who did you talk to about it (e.g. family, friends)?

2.3. Who or what contributed to your consulting a doctor about your complaints?

2.4. How did you experience your first consultation with a doctor about $i t$ ?

2.5. If you changed your doctor during this time, how and why did this happen?

The free-text information provided by the respondents varied in form, and quality and scope, ranging from single keywords to detailed descriptions. The data material was evaluated in parallel by two independent researchers based on the content-structuring content analysis technique according to Kuckartz [22] (p. 97ff.). The available information was captured in a methodical, controlled reduction process and transferred into a structured category system. Due to the large amount of text material, the investigators were able to exclude cases of ambiguity due to unclear statements and switch to alternative data material if their interpretations of a given text passage differed.

To improve the understanding of a respondent's statement, they were also permitted to take responses relating to other questions of

${ }^{2}$ Funded by the Federal Ministry of Education and Research (BMBF), grant no. 01GY1316

${ }^{3}$ The procedure was approved by the ethics committee and the data protection officer of Hannover Medical School (MHH).

${ }^{4}$ Participants P3, P11, P15, P26, P27, P38, P44 and P77 the online questionnaire into account if relevant to the evaluated question. The results are presented below, along with selected original quotations, which are representative examples of statements by other respondents. ${ }^{5}$

\section{Development of the category system}

Our first attempt to develop a category system by deriving typical patterns of care had to be abandoned due to the unexpectedly high heterogeneity and lack of precision of the data (incomprehensible, non-chronological and/or missing information). However, it was possible to identify two aspects of potential importance for improving the quality of care of endometriosis patients:

- Time of onset of symptoms: The majority of study participants had an early onset of endometriosis symptoms in adolescence, very soon after menarche, while a smaller proportion reported a later onset in adulthood, following initially unremarkable years of menstruation. This age difference raises the question of whether differences in the time of onset could influence medical care in the further course of the disease.

- Obstacles to decision-making: It also became clear that women in the two groups were influenced to a different extent regarding the decision of whether and when to seek treatment. The analysis facilitated the identification of key decision-makers and possible influencing factors, which should help to develop approaches and recommendations for better care of endometriosis patients.

To develop a new category system for content analysis (Table 1), we defined the actors involved in decision-making (the endometriosis patients, actors in their social environment and health care providers) as main categories, placing them, in a deductive manner, at the center of the evaluation. This procedure was guided by both the research question and by the items on the online EHC study questionnaire. Inductively, the frequency with which health care providers ${ }^{6}$ and social actors (mothers, sisters, friends, colleagues, etc.) were mentioned was also used for derivation of the main categories. Subcategories were then developed inductively from the available text material, including possible inhibitory or supportive factors influencing decision-making regarding the use of medical services.

\begin{tabular}{|c|c|c|c|}
\hline \multicolumn{2}{|r|}{ Main Categories } & \multirow{2}{*}{\multicolumn{2}{|c|}{$\begin{array}{c}\text { Subcategories } \\
\begin{array}{c}\text { Factors influencing decision- } \\
\text { making }\end{array}\end{array}$}} \\
\hline & Decision-makers & & \\
\hline \multirow[t]{2}{*}{$\mathrm{C} 1$} & Endometriosis patients & C1.1 & Ignorance of patients \\
\hline & & $\mathrm{C} 1.2$ & Suppression \\
\hline \multirow[t]{2}{*}{$\mathrm{C} 2$} & Social actors & $\mathrm{C} 2.1$ & $\begin{array}{l}\text { Ignorance of social } \\
\text { actors }\end{array}$ \\
\hline & & $\mathrm{C} 2.2$ & Personal experience \\
\hline $\mathrm{C} 3$ & Health care providers & C3.1 & Misjudgment \\
\hline
\end{tabular}

The results for the individual categories are presented along with typical original quotations in the following. As the significance of the time of onset of symptoms relative to the start of treatment of endometriosis in Germany was a particular focus of study, we compared the responses of women with early onset endometriosis (EOE) symptoms versus late onset endometriosis (LOE) symptoms for the respective categories [22]. Twelve out of 102 questionnaires had to be excluded due to unusability or ambiguity that impeded proper classification (see above), leaving an actual sample size of 90 . An early onset group of 63 women with an average age of onset of 14.1 years and an average diagnostic delay of 16.4 years, and a late onset group of 27 women with an average age of onset of 23.9 years and an average diagnostic delay of 6.9 years ${ }^{7}$ were clearly identified.

\footnotetext{
${ }^{5}$ Numbers in brackets indicate the chronologically documented responses (P1 to P102) and the respective response numbers (1.1 to 2.5$)$.

${ }^{6}$ Doctors were most commonly mentioned, but psychologists, psychologists, psychiatrists, psychiatrists and various therapeutic professions were also mentioned occasionally.

${ }^{7} \mathrm{O} 13$ women, concrete annual figures were missing
} 


\section{Results}

Very little demographic information was available on the study population due to anonymization of the data. The ages of the study participants ranged from 17 to 57 years (mean: 38.4 years). About $70 \%$ of participants lived in a stable relationship, $22 \%$ were single and $7 \%$ were divorced. There were 77 specific statements about the time of the final diagnosis, 20 of which were more than 10 years old.

\section{Comparison according to the time of onset of symptoms}

\begin{tabular}{|c|c|}
\hline Early onset group & Late onset group \\
\hline \multirow{2}{*}{$\begin{array}{l}\text { "At the age of 12, in August } \\
\text { 1984, I got my first period and from } \\
\text { day one I had severe cramp-like } \\
\text { pain and very heavy bleeding. I am } \\
\text { convinced that endometriosis was } \\
\text { the cause even then, even though } \\
\text { it was diagnosed much later (in } \\
\text { February 2000)". (P13; 1.1) }\end{array}$} & "In her early 20s, in 1988." (P73; \\
\hline & $\begin{array}{l}\text { "At that point of time } \\
\text { [menarche] I never had severe pain, } \\
\text { only "normal" pelvic pain." [P1; 1.2) }\end{array}$ \\
\hline $\begin{array}{l}\text { "From the beginning, } \\
\text { menstruation was never completely } \\
\text { painless; from the 2nd or } 3 r d \\
\text { menstrual cycle onwards, it was } \\
\text { so unpleasant that I had to take } \\
\text { painkillers to be able to go about my } \\
\text { daily life. It got worse almost from } \\
\text { cycle to cycle." (P102; 1.1) }\end{array}$ & $\begin{array}{l}\text { "During abdominal surgery in } \\
\text { August 2004, I was } 36 \text { years old; I } \\
\text { had myself sterilized to stop taking } \\
\text { hormones. Only a few months later } \\
\text { I got the first complaints. During } \\
\text { menstruation, I had a burning } \\
\text { sensation, which I thought was in } \\
\text { my vagina." (P100; 1.1) }\end{array}$ \\
\hline
\end{tabular}

Approximately two-thirds of the respondents reported a very early onset of endometriosis symptoms, starting with the onset of menarche or shortly thereafter (P13). They listed a wide range of complaints such as pelvic pain, nausea, intestinal complaints, headaches and heavy bleeding, which often worsened in the course of the disease (P102). In contrast, a smaller proportion of study participants had a late onset of endometriosis symptoms, with no symptoms or only mild symptoms in the early years after menarche (P1).

\section{Categories}

\begin{tabular}{|c|c|}
\hline Early onset group & Late onset group \\
\hline $\begin{array}{l}\text { "From } 1977 \text { to } 1991, \text { I thought } \\
\text { menstrual pain was normal because } \\
\text { it was the same with my mother. } \\
\text { It wasn't until 1991, when spotting } \\
\text { occurred, that I actually consulted my } \\
\text { gynecologist." (P96; 1.3) }\end{array}$ & $\begin{array}{l}\text { "I first noticed the symptoms in early } \\
\text { November } 2013 \text {. They manifested } \\
\text { themselves as severe pelvic pain. One } \\
\text { day later, I had to walk bent over, } \\
\text { could only sit to a limited extent and } \\
\text { could not eat or drink anything, as the } \\
\text { food was literally weighing heavy on } \\
\text { my stomach and hurt even more..." } \\
(P 48 ; 1.1)\end{array}$ \\
\hline $\begin{array}{l}\text { "I regularly suffered very badly during } \\
\text { my period. However, I thought that } \\
\text { the pain was "normal" and part of } \\
\text { being a woman. }(P 49 ; 1.3)\end{array}$ & $\begin{array}{l}\text { "Since I am a nurse myself and I never } \\
\text { had problems with my period, I went } \\
\text { to the gynecologist quite quickly. I was } \\
\text { very worried as I had never before had } \\
\text { pain during menstruation." (P50;1.2) }\end{array}$ \\
\hline
\end{tabular}

C1: Endometriosis patients: Many patients with a very early onset of endometriosis symptoms in adolescence reported that, initially, they did not recognize the pathological significance of their symptoms (P49) and, thus, did not feel compelled to seek medical advice (P96). Conversely, women with an onset of symptoms at a later stage of life were able to recognize their pathological significance more quickly (P48). They realized that the change in their body was a health-related problem and promptly contacted a doctor (P50).

\begin{tabular}{|l|l|}
\hline \multicolumn{1}{|c|}{ Early onset group } & \multicolumn{1}{|c|}{ Late onset group } \\
\hline "I often felt insecure because I did \\
not know what was going on" (P93; & "I felt very bad and I didn't know \\
1:3) & what was happening to me." (P19; \\
\hline "I always had menstrual pain from & "[...] Through internet research, I \\
the age of 14 on, and I thought it was & came across the term endometriosis \\
normal because I didn't know any & and had a suspicion, but thought \\
it could not actually be that. I \\
hetter." (P101; 1.2) \\
had light bleeding (which got even \\
weaker after the miscarriage and \\
the onset of pain). At one point \\
(when I was 29), the pain was so \\
extreme that I was taken to hospital \\
in an ambulance [..... (P7;1.3)
\end{tabular}

C1.1: Ignorance of patients: Content analysis of the women's statements suggests that those individuals who developed endometriosis symptoms at an early age, very soon after the onset of menarche, had greater difficulty recognizing the need for treatment. Due to the "ignorance of youth", teenagers do not know what is "normal" and what is not (P101). The initial lack of motivation of women with early onset endometriosis symptoms can therefore be explained by their ignorance of essential facts about menstruation, as is reflected in the information provided by these study participants (P93). The analyzed quotations show that women with a later onset of complaints were also initially quite insecure due to a lack of knowledge (P19). However, in contrast to the women with an early onset of symptoms, late onset endometriosis sufferers very quickly worked towards obtaining medical clarification of their symptoms, either on their own initiative or after prompting by someone in their social environment (P7).

\begin{tabular}{|l|}
\hline \multicolumn{1}{|c|}{ Early onset group } \\
\hline $\begin{array}{l}\text { "Insecurity, otherwise too busy doing other things. Honestly, I never thought } \\
\text { about it being a disease. I attributed it all to stress in college." (P43; 1.3) }\end{array}$ \\
\hline "I perceived the symptoms as normal and did not attach any particular \\
significance to them." (P47; 1.3)
\end{tabular}

C1.2: Suppression: Individual reports from women in the early onset group indicate that they initially suppressed their perception of the symptoms due, among other things, to external influences. The quotations of study participants P43 and P47 clearly demonstrate this. No comparable statements could be found in the quotations from women in the late onset group.

\begin{tabular}{|c|c|}
\hline Early onset group & Late start group \\
\hline $\begin{array}{l}\text { "With my mother and my sister } \\
\text { and two close friends. I didn't } \\
\text { tell anyone else and pretended } \\
\text { to be strong." (P80; 2.2) }\end{array}$ & $\begin{array}{l}\text { "Family. My oldest sister often } \\
\text { also experienced the same thing. } \\
\text { My grandmother had also dealt } \\
\text { with severe menstrual pain. } \\
\text { Friends didn't want to hear } \\
\text { about it." (P31; 2.2) }\end{array}$ \\
\hline $\begin{array}{l}\text { "With my mother, who had little } \\
\text { understanding for my problem." } \\
(P 30 ; 2.2)\end{array}$ & $\begin{array}{l}\text { "Partner, mother, best friend, no } \\
\text { one else until diagnosed." (P39; } \\
2.2)\end{array}$ \\
\hline $\begin{array}{l}\text { "There was no one I was able to } \\
\text { talk to about it. (P13; } 2.2)\end{array}$ & $\begin{array}{l}\text { "Friends and parents, who were } \\
\text { annoyed and thought I needed } \\
\text { more attention. }(P 1 ; 2.2)\end{array}$ \\
\hline
\end{tabular}


C2: Social actors: Apart from the endometriosis patients themselves, people in their social environment influenced their decision-making process on how to deal with their disease complaints. The vast majority of study participants (regardless of the time of onset of endometriosis symptoms) stated that they had discussed their health problems with close confidants (P31, P39, P80). However, these individuals did not always show understanding for the patients' problems (P1, P30, P31). Some women do not seem to have found any suitable confidants in their environment (P13). Patients from both groups equally reported negative experiences with people from their social environment.

\begin{tabular}{|l|l|}
\hline \multicolumn{1}{|c|}{ Early onset group } & \multicolumn{1}{|c|}{ Late onset group } \\
\hline $\begin{array}{l}\text { With all... nobody had any } \\
\text { idea what it could be; in } \\
\text { retrospect, nobody knew about } \\
\text { endometriosis" (P66; 2.2) }\end{array}$ & \\
\hline "I suffered very badly for & "My mother said it might not \\
years. My mother told me that & be normal abdominal pain, but \\
menstrual pain was normal & some gynecological problem." \\
and that I would have to endure & (P19; 2.3) \\
it until menopause. A doctor & \\
could not help me there either. & \\
My friends told me that they & \\
also had menstrual pain, such & \\
a slight pulling sensation, so I & \\
shouldn't be so fussy. (P13; 1.2) & \\
\hline "Partner, later also with family & "I had talked to my mother \\
and close friends. My sister also & and my boyfriend and his \\
has endometriosis (diagnosed & mother at the time, because \\
Sept. 2011). She had completely & they both worked in the hospital \\
different complaints, so we did & as well. Finally, this led to the \\
not think it was endometriosis & assumption of endometriosis." \\
in the beginning." (P13; 1.2) "My & (P48; 2.2) \\
sister also has endometriosis & \\
(diagnosed Sept. 2011). (P12; & \\
2.2) & \\
\hline
\end{tabular}

C2.1: Ignorance of social actors: The opinion of social actors is particularly important for adolescents with an early onset of typical endometriosis symptoms. On the one hand, teenagers do not (yet) have sufficient health-related knowledge and, on the other hand, due to their age, they are (still) strongly dependent on the decision-making competence of elders, particularly, their parents. The available data indicates that the decision of young people to seek treatment for endometriosis-associated problems tends to be delayed by actors in their immediate environment - even if other women in the family have experienced endometriosis (P12) or corresponding symptoms (P13). Ignorance of social actors about the pathological significance of the symptoms is an important risk factor for misjudgment of the symptoms. In some cases, this occurred even though the patients had discussed their condition with several confidants (P66). Conversely, women in the group with an onset of symptoms later in life were encouraged by people in their social environment to obtain early medical clarification of their symptoms (P55, P19 and P48).

C2.2: Personal experience: Women in the early onset group typically reported that because their mothers and/or sisters etc. had also experienced painful periods or other complaints, they initially considered their complaints to be "normal" and did not seek treatment (P96, P10).

Although some of the women in the late onset group had mothers with symptoms typical of endometriosis, the evidence does not suggest that their diagnosis was delayed. Apparently, these women took the initiative to seek early medical clarification of their symptoms without outside influence (P50, P75).

\begin{tabular}{|c|c|}
\hline Early onset group & Late onset group \\
\hline $\begin{array}{l}\text { "From the beginning, with my } \\
\text { mother. But she had the same } \\
\text { symptoms and so we both } \\
\text { thought that it was nothing } \\
\text { pathological, but that it was the } \\
\text { same for us. Iguess you have to } \\
\text { go through that. There's nothing } \\
\text { you can do. ... Once you have } \\
\text { kids, it'll be better." (P96; 2.2) }\end{array}$ & $\begin{array}{l}\text { "Since I have never had any } \\
\text { problems (heavy bleeding, } \\
\text { pain) before. My body is trying } \\
\text { to tell me something with this. } \\
\text { My mother also had several } \\
\text { miscarriages and heavy } \\
\text { bleeding. (P50; 2.3) }\end{array}$ \\
\hline $\begin{array}{l}\text { "My family knew about it and } \\
\text { avoided me on those days. I } \\
\text { talked about it with my mother. } \\
\text { She also had a lot of pain for a } \\
\text { long time during her periods." } \\
(\text { P10; 2.2) }\end{array}$ & $\begin{array}{l}\text { "I myself wanted medical } \\
\text { clarification of the complaints. } \\
\text { So I didn't need a third party to } \\
\text { push me to see a doctor." (P75; } \\
\text { 2.3) }\end{array}$ \\
\hline
\end{tabular}

C3: Health care providers: Apparently, the first "hurdle" to overcome in improving the treatment of endometriosis lies in the patients themselves and in some cases, to a greater extent, the actors in their social environment. However, some respondents also reported obstacles in connection with medical care and support (P7). Several participants in the study - irrespective of the time of onset of their complaints - reported that the condition had not been diagnosed despite a "marathon" of doctor visits (P4, P23, P100).

\begin{tabular}{|l|l|}
\hline \multicolumn{1}{|c|}{ Early onset group } & \multicolumn{1}{|c|}{ Late onset group } \\
\hline "I consulted 6 different & "Visited several doctors. First, \\
gynecologists, asked my family & my gynecologist, who didn't \\
doctor for advice, went to the & want to or couldn't help me. \\
emergency room of a hospital & He never did an ultrasound of \\
several times and spoke to & my stomach or referred me to \\
doctors there. But all I heard & another doctor. Then my family \\
was that pain was normal & doctor, who referred me to a \\
and that every woman had a & urologist. I got the diagnosis \\
different perception of pain. & from him." (P100; 2.1) \\
I was just a woman with low \\
tolerance for pain." (P4; 2.1)
\end{tabular}

C3.1 Misjudgment: Another important factor in the long delay in diagnosis is that physicians often did not take the endometriosisassociated complaints seriously for a long time (P4). Our analysis revealed distinct differences between individuals with an early and a late onset of endometriosis symptoms. Almost all women in the early onset group reported that, initially, they were not taken seriously (P82), the treating physician had told them that their pain was "normal" and that they were healthy (P14) and/or that the physician dismissed their pain and recommended the use of painkillers or a hot water bottle (P41). In the late onset group, on the other hand, respondents typically reported that their health care providers had taken a serious look at their symptoms, taken appropriate steps quickly (P59, P), and made a thorough diagnosis (P60).

\begin{tabular}{|l|l|}
\hline \multicolumn{1}{|c|}{ Early onset group } & \multicolumn{1}{|c|}{ Late onset group } \\
\hline "I was very insecure. [...] When & "It was a very good experience \\
I spoke to my doctors at the time & because my doctorimmediately took \\
(I have seen many doctors), they & me seriously, arranged for various \\
did not take me seriously. I was & blood tests and after getting the \\
hoping for help and was labeled & results (increased tumor markers), \\
hypersensitive." (P82; 1.3) & immediately recommended \\
& further examinations, including \\
& laparoscopy after the other \\
& examinations had brought no \\
& clarification". (P59; 1.5) \\
\hline
\end{tabular}




\begin{tabular}{|c|c|}
\hline $\begin{array}{l}\text { "I was insecure about which types } \\
\text { of pain are normal and which are } \\
\text { not normal. Was I just making a } \\
\text { fuss or did the complaints have a } \\
\text { cause? Numerous different doctors } \\
\text { assured me that I was healthy and } \\
\text { so I accepted the symptoms at first. } \\
\text { (P14; } 1.3)\end{array}$ & $\begin{array}{l}\text { "My doctor at the time did an } \\
\text { ultrasound and, based on myclinical } \\
\text { picture, was of the opinion that this } \\
\text { could be incipient endometriosis. } \\
\text { At first I refused the laparoscopy, } \\
\text { which would have helped to make } \\
\text { a clear diagnosis, and wanted to try } \\
\text { the hormonal option. He prescribed } \\
\text { the three-month injection twice [...]. } \\
\text { It actually got better little by little." } \\
\text { (P50; 1.5) }\end{array}$ \\
\hline $\begin{array}{l}\text { "I was put off or not taken seriously } \\
\text { at all. They did not investigate what } \\
\text { the cause of the complaints was at } \\
\text { all, or ask me any detailed questions } \\
\text { about the pain. "Take painkillers. A } \\
\text { hot-water bottle also helps. That's } \\
\text { just the way it is." were the only } \\
\text { statements I heard. (P41; 1.3) }\end{array}$ & \\
\hline $\begin{array}{l}\text { "I had the same experience as } \\
\text { all other women. One goes to the } \\
\text { doctor, you are not taken seriously, } \\
\text { you go to the next doctor, and are } \\
\text { not taken seriously, and so on and so } \\
\text { forth. It was a time of helplessness, } \\
\text { but also a time offear." (P4; 1.3) }\end{array}$ & $\begin{array}{l}\text { "[...] But I didn't go to the } \\
\text { gynecologist again until I was } 19 . \\
\text { He also suspected something and } \\
\text { performed a laparoscopy, and then } \\
\text { the diagnosis came immediately" } \\
(P 60,1.3) \text {. }\end{array}$ \\
\hline
\end{tabular}

\section{Discussion}

\section{Discussion of the methods}

Many participants who were successfully recruited through the broad-based recruitment strategy of the EHC study were very disappointed that they were unable to share their experiences in a face-to-face interview. This, combined with the considerable time requirement, may explain the low response rate of $48 \%$. Furthermore, based on the sometimes very impressive descriptions of the women's suffering, bias in favor of seriously ill and more severely afflicted women with negative experiences in connection with the medical treatment of endometriosis can be assumed. It was not possible to clearly classify each participant as having an early or late onset of endometriosis complaints due to ambiguity. Four questionnaires were completely unusable and eight had to be excluded from the analysis due to ambiguity, leaving an actual sample size of 90 .

\section{Discussion of the results}

The problem of unreasonably long delays in the diagnosis of endometriosis (up to 10 years in some cases) is internationally discussed and deplored $[13,18]$. Even though patient self-reports are subject to a certain degree of uncertainty due to various influencing factors $^{8}$, the results of the present evaluation of free text data from the online survey make it clear that, for a large proportion of patients, various factors have an effect on the time between the onset of symptoms and establishment of the diagnosis and can lead to a delay in diagnosis. Particularly, evidence suggests that the length of the delay in diagnosis differs significantly between women with a very early onset of typical endometriosis symptoms and those whose endometriosis symptoms only occur later in life $[16,23]$. The text material analyzed in this study gave further insights into the possible reasons for the delay in diagnosis.

The result of this study - which was by all means selective - shows that the majority of participants initially perceived their symptoms as "normal". This is a phenomenon already known in the literature [24]. Nevertheless, there seem to be clear differences in the way the two groups dealt with the symptoms.

The results of other trials indicate that young females who experience pelvic pain at a very early age (between 11 and 15 years old),

${ }^{8}$ Memory bias, unclear definition of symptoms in need of treatment, disagreement about the Gold Standard for diagnosis, access to the health system, etc. possibly even at menarche, have a high risk of a delayed diagnosis of endometriosis [25]. One possible explanation is that girls of this age lack knowledge and experience of normal menstrual cycles, which can lead to misinterpretation of the pathological value of the symptoms. Their most important and often only sources of information are family members and friends, who - partly also based on their own experience - tend to "normalize" and "down play" the symptoms and describe them as being a woman's fate. Adolescents' access to doctors and other health care professionals is strongly dependent on their parents or guardians who, in turn, must recognize the possible pathological significance of the youngster's complaints. The search for further valid sources of relevant health care information is certainly an overtaxing challenge for young people in this age group.

In this respect, it is not surprising that they tend to adopt the opinions of their closest confidants in the social environment and do not question them for years. In many cases, this situation does not change unless they have further progression of the disease or an unfulfilled desire to conceive and undergo further examinations for medical clarification. Frequently, valuable time is lost and the diagnosis is delayed, during which time the disease can progress due to the lack of treatment [26].

Participants with an early onset of endometriosis symptoms a few years after menarche seemed to recognize the pathological significance of the symptoms sooner and take appropriate measures more quickly. Those who are older at onset tend to have better access to sources of information outside their own social environment and are better able to process this data and better able to make independent decisions. Due to their greater independence, they have the chance to become active independently of family influence and to demand medical clarification of their symptoms.

As has already been shown in other studies $[12,13,16]$, doctors and other health care professionals play an important role in the diagnostic delay. The results of the present qualitative survey have shown that there is still a great need for improved information of medical professionals through education and (compulsory) further training as well as for quality assurance through the establishment of specialized endometriosis centers [25, 27-29]. A large proportion of the study participants included in the present analysis reported that they were not taken seriously by their physicians and that, often, no solution to their problem was found despite numerous consultations with doctors. For example, the assumption by several doctors that their patients could not have endometriosis because they were too young is a sign of serious ignorance. The respondents described the behavior of their treating physicians as putting off, playing down, deriding and "normalizing". This is a sign of insufficient treatment of the women, which often results in a delayed diagnosis $[17,30]$.

A recent publication from the Netherlands underlines the inequality of treatment of women: the authors found that general practitioners are reluctant to refer women for further diagnosis of possible endometriosis-related complaints, especially if they are very young [21]. Caught in a recurrent cycle of pain, the cause of which cannot be determined, some of the patients tried to find information about the problem by doing their own research in order to be able to be more specific (goal-oriented) when speaking to the physicians they consulted. Besides information material from health insurance companies or medical practices, the Internet was the main medium that helped the women to find possible clues to the cause of their complaints. One patient very succinctly stated how this self-initiative behavior is the way to success as follows:

"[...] that one must, however, go to [doctors] with great selfconfidence and, in order for them to make a rapid diagnosis, e the patient herself must make independent assumptions ... which can't really be the point." (P32, 2.4)

In this respect, the results obtained here confirm and complement the findings of previous studies $[13,16]$ showing that a lack of knowledge and awareness of the treating physician has an adverse effect on women with symptoms of endometriosis, particularly if the patient is very young $[17,30]$. 
However, our evaluation of the available data has also shown that it will not be sufficient to bring about improvement exclusively at the level of the treating physician. Population-wide education and information is at least as important because, as Elaine Denny stated in 2004:

"Diagnosis of this condition is a social as well as a clinical process, and widely held medical and societal values are influential in the way in which symptoms are interpreted and responded to. [19].

It is particularly important that girls acquire a better knowledge of the cyclical physiological processes of their bodies as early as puberty in order to be able to recognize normal and pathological changes [31,32]. At this age, they do not go to a doctor on their own initiative, but are dependent on their mothers, sisters etc. to arrange for or at least support their consultation with a doctor. A prerequisite for population-wide improvement in the level of knowledge is the development of target group-specific information materials and the identification of comprehensive access routes [33-36]. In this time of intensive use of social media and Google as ubiquitous advisors, an attempt should be made to use these possibilities for improving the information situation at the population level. From a societal perspective, these measures are also recommended to reduce the delay in diagnosis of endometriosis since a longer delay in diagnosis is not only associated with significantly adverse effects on the course of the disease and the quality of life, but also with high costs [8].

\section{Conclusions}

The results of the present analysis confirm the findings of other studies indicating that misjudgment and ignorance of the signs and symptoms are the most important reasons for the delayed diagnosis of endometriosis. Thus, it is necessary to develop comprehensive and target group-specific information offerings. Our analysis identified girls who show typical symptoms of endometriosis at a very early stage, often already at menarche, as a particularly relevant target group. This indicates an urgent need to educate adolescent females at school and via social media about the characteristics of normal and pathological menstruation. Further measures should be taken to improve the level of knowledge of the general population. Their aim should be to raise the awareness of actors in their social environment to the typical signs and symptoms of endometriosis in order to reduce the delay in diagnosis. In addition, the topic of endometriosis should be made a compulsory part of gynecological and general medical training. As with other diseases, it should be obligatory for doctors to provide good-quality, comprehensive, patient-oriented information about endometriosis in their practices and hospitals.

One of our patients summed it up as follows:

"The topic must be more present - unfortunately, not only in the case of many doctors, but also in the media." $(P 26,8.4)$

We can only endorse her conclusion.

\section{References}

1. Eisenberg VH, Weil C, Chodick G, Shalev V. Epidemiology of endometriosis: a large population-based database study from a healthcare provider with 2 million members. BJOG : an international journal of obstetrics and gynaecology 2018; 125(1): $55-62$

2. Rogers PAW, D'Hooghe TM, Fazleabas A et al. Defining future directions for endometriosis research: workshop report from the 2011 World Congress of Endometriosis In Montpellier, France. Reproductive sciences (Thousand Oaks, Calif.) 2013; 20(5): $483-499$

3. Abbas S, Ihle P, Köster I, Schubert I. Prevalence and incidence of diagnosed endometriosis and risk of endometriosis in patients with endometriosis-related symptoms: findings from a statutory health insurance-based cohort in Germany. European journal of obstetrics, gynecology, and reproductive biology 2012; 160(1): $79-83$

4. Morotti M, Vincent K, Becker CM. Mechanisms of pain in endometriosis. European journal of obstetrics, gynecology, and reproductive biology 2017; 209: 8 - 13

5. Rowe H, Quinlivan J. Let's not forget endometriosis and infertility amid the covid-19 crisis. Journal of psychosomatic obstetrics and gynaecology 2020; 41(2): $83-85$

6. Kundu S, Wildgrube J, Schippert C, Hillemanns P, Brandes I. Supporting and Inhibiting Factors When Coping with Endometriosis From the Patients' Perspective. Geburtshilfe Frauenheilkd 2015; 75(5): 462 - 469

7. Lamvu G, Antunez-Flores O, Orady M, Schneider B. Path to diagnosis and women's perspectives on the impact of endometriosis pain. Journal of Endometriosis and Pelvic Pain Disorders 2020; 12(1): $16-25$

8. Surrey E, Soliman AM, Trenz H, Blauer-Peterson C, Sluis A. Impact of Endometriosis Diagnostic Delays on Healthcare Resource Utilization and Costs. Advances in therapy 2020; 37(3): 1087 - 1099

9. Brandes I. Lebensqualität von Endometriose-Patientinnen. Geburtshilfe Frauenheilkd 2007; 67(11): 1227 - 1231

10. Simoens S, Dunselman G, Dirksen C et al. The burden of endometriosis: costs and quality of life of women with endometriosis and treated in referral centres. Human reproduction (Oxford, England) 2012; 27(5): 1292 - 1299

11. Prast J, Oppelt P, Shamiyeh A, Shebl O, Brandes I, Haas D. Costs of endometriosis in Austria: a survey of direct and indirect costs. Archives of gynecology and obstetrics 2013; 288(3): 569 - 576

12. Ballard K, Lowton $\mathrm{K}$, Wright J. What's the delay? A qualitative study of women's experiences of reaching a diagnosis of endometriosis. Fertility and sterility 2006; 86(5): 1296 - 1301

13. Hudelist G, Fritzer N, Thomas A et al. Diagnostic delay for endometriosis in Austria and Germany: causes and possible consequences. Human reproduction (Oxford, England) 2012; 27(12): $3412-3416$

14. Hadfield R, Mardon H, Barlow D, Kennedy S. Delay in the diagnosis of endometriosis: a survey of women from the USA and the UK. Human Reproduction 1996; 11(4): $878-880$

15. Garry R. Diagnosis of endometriosis and pelvic pain. Fertility and sterility 2006; 86(5): 1307-9; discussion 1317

16. Staal AHJ, van der Zanden M, Nap AW. Diagnostic Delay of Endometriosis in the Netherlands. Gynecologic and obstetric investigation 2016; 81(4): $321-324$

17. van der Zanden M, Arens MWJ, Braat DDM, Nelen WLM, Nap AW. Gynaecologists' view on diagnostic delay and care performance in endometriosis in the Netherlands. Reproductive biomedicine online 2018; 37(6): 761 - 768

18. Kiesel L, Sourouni M. Diagnosis of endometriosis in the 21st century. Climacteric : the journal of the International Menopause Society 2019; 22(3): 296 - 302

19. Denny E. 'You are one of the unlucky ones': delay in the diagnosis of endometriosis. Diversity in Health and Social Care 2004; $1: 39-44$

20. Riazi H, Tehranian N, Ziaei S, Mohammadi E, Hajizadeh E, Montazeri A. Patients' and physicians' descriptions of occurrence and diagnosis of endometriosis: a qualitative study from Iran. BMC women's health 2014; 14: 103

21. van der Zanden M, Teunissen DAM, van der Woord IW, Braat DDM, Nelen WLDM, Nap AW. Barriers and facilitators to the timely diagnosis of endometriosis in primary care in the Netherlands. Family practice 2020; 37(1): 131 - 136

22. Kuckartz U. Qualitative Inhaltsanalyse. Methoden, Praxis, Computerunterstützung. 3., überarbeitete Auflage, OnlineausgabeAufl. Weinheim, Basel: Beltz Juventa, 2016

23. Arruda MS. Time elapsed from onset of symptoms to diagnosis of endometriosis in a cohort study of Brazilian women. Human Reproduction 2003; 18(4): 756 - 759

24. Sachedina A, Todd N. Dysmenorrhea, Endometriosis and Chronic Pelvic Pain in Adolescents. Journal of clinical research in pediatric endocrinology 2020; 12(Suppl 1): 7 - 17

25. Ghai V, Jan H, Shakir F, Haines P, Kent A. Diagnostic delay for superficial and deep endometriosis in the United Kingdom. 
Journal of obstetrics and gynaecology : the journal of the Institute of Obstetrics and Gynaecology 2020; 40(1): 83 - 89

26. Matsuzaki S, Canis M, Pouly J-L, Rabischong B, Botchorishvili R, Mage G. Relationship between delay of surgical diagnosis and severity of disease in patients with symptomatic deep infiltrating endometriosis. Fertility and sterility 2006; 86(5): 1314-6; discussion 1317

27. Ebert AD, Jackisch D, Mueller $\mathrm{M}$ et al. Endometriosezentren verschiedener Stufen zur Verbesserung der medizinischen Versorgungsqualität sowie der ärztlichen Fort- und Weiterbildung. GynEndo 2008; 18(2): 62 - 68

28. Schweppe KW, Ebert AD, Kiesel L. Endometriosezentren und Qualitätsmanagement. Gynäkologe 2010; 43(3): 233 - 240

29. Rogers PAW, Adamson GD, Al-Jefout $M$ et al. Research Priorities for Endometriosis. Reproductive sciences (Thousand Oaks, Calif.) 2017; 24(2): $202-226$

30. van der Zanden M, Nap AW. Knowledge of, and treatment strategies for, endometriosis among general practitioners. Reproductive biomedicine online 2016; 32(5): 527 - 531

31. Seear K. The etiquette of endometriosis: stigmatisation, menstrual concealment and the diagnostic delay. Social science
\& medicine (1982) 2009; 69(8): 1220 - 1227

32. Adams Hillard PJ. Menstruation in adolescents: what do we know? And what do we do with the information? Journal of pediatric and adolescent gynecology 2014; 27(6): 309 - 319

33. Carneiro MM, Farace BL, Ribeiro LSdC et al. Using social media to educate women and healthcare providers on endometriosis: preliminary results. JBRA assisted reproduction 2020; 24(1): 9 $-12$

34. Hirsch M, Aggarwal S, Barker C, Davis CJ, Duffy JMN. Googling endometriosis: a systematic review of information available on the Internet. American Journal of Obstetrics and Gynecology 2017; 216(5): 451-458.e1

35. Shadbolt NA, Parker MA, Orthia LA. Communicating endometriosis with young women to decrease diagnosis time. Health promotion journal of Australia : official journal of Australian Association of Health Promotion Professionals 2013; 24(2): $151-154$

36. Wilson S, Mogan S, Kaur K. Understanding the role of Facebook to support women with endometriosis: A Malaysian perspective. International journal of nursing practice 2020: e12833 